\title{
One-Dimensional $\mathrm{Sb}_{2} \mathrm{Se}_{3}$ Nanorods Synthesized through a Simple Polyol Process for High-Performance Lithium-Ion Batteries
}

\author{
Yuan Tian $\mathbb{D}^{1},{ }^{1}$ Zhenghao Sun $\mathbb{D}^{1},{ }^{1}$ Yan Zhao ${ }^{\mathbb{D}},{ }^{1}$ Taizhe Tan, ${ }^{2}$ Hui Liu $\mathbb{D}^{1}{ }^{1}$ \\ and Zhihong Chen ${ }^{3}{ }^{3}$ \\ ${ }^{1}$ School of Materials Science and Engineering, Research Institute for Energy Equipment Materials, Hebei University of Technology, \\ Tianjin 300130, China \\ ${ }^{2}$ Synergy Innovation Institute of GDUT, Heyuan, 517000 Guangdong Province, China \\ ${ }^{3}$ Shenyang Institute of Automation, Guangzhou, Chinese Academy of Sciences, 511458, China
}

Correspondence should be addressed to Yan Zhao; yanzhao1984@hebut.edu.cn, Hui Liu; liuhuihebut@163.com, and Zhihong Chen; chenzhihong1227@sina.com

Received 29 June 2018; Accepted 2 September 2018; Published 22 November 2018

Academic Editor: Lavinia Balan

Copyright (C) 2018 Yuan Tian et al. This is an open access article distributed under the Creative Commons Attribution License, which permits unrestricted use, distribution, and reproduction in any medium, provided the original work is properly cited.

The good crystalline $\mathrm{Sb}_{2} \mathrm{Se}_{3}$ nanorods have been successfully synthesized through a simple polyol process. The detailed morphological and structural characterizations reveal that nanorods are composed of $\mathrm{Sb}_{2} \mathrm{Se}_{3}$ single crystals oriented along the [120] orientation; the tiny $\mathrm{Sb}_{2} \mathrm{Se}_{3}$ nanorods are found to display a higher crystallinity with respect to thick $\mathrm{Sb}_{2} \mathrm{Se}_{3}$ nanorods. The nanorods have been applied as anode materials for lithium-ion batteries, with tiny $\mathrm{Sb}_{2} \mathrm{Se}_{3}$ nanorod anodes delivering the relatively high discharge capacity of $702 \mathrm{mAh} \mathrm{g}^{-1}$ at $0.1 \mathrm{C}$ and could maintain the capacity of $230 \mathrm{mAh} \mathrm{g}^{-1}$ after 100 cycles. A more stable cycling performance is also demonstrated on tiny $\mathrm{Sb}_{2} \mathrm{Se}_{3}$ nanorods, which is ascribed to their more pronounced one-dimensional nanostructure.

\section{Introduction}

With the increase of the world energy demand and the decrease of resources, Li-ion batteries (LIBs) are one of the most important electrical energy storage devices and are widely used in various portable electronic devices due to its relatively high energy density [1-7]. Nowadays, the lowcost graphite material is the most popular anode material used in commercial LIBs $[8,9]$. However, graphite anodes possess a low theoretical specific capacity $\left(372 \mathrm{mAhg}^{-1}\right)$, which could hardly meet the requirements for high capacity and safety in practical energy storage application such as power stations. To improve the specific capacity of anode materials for LIBs, fabricating and testing new anode materials have become the focus of a multitude of scientific researches, such as metal oxides and metal sulfides. Among them, metal chalcogenides have emerged as promising anode materials for LIBs. In particular, researchers have fabricated antimony-based chalcogenide materials such as $\mathrm{Sb}_{2} \mathrm{O}_{3}$ nanomaterials and $\mathrm{Sb}_{2} \mathrm{Se}_{3}$ thin films, which could sensibly increase capacity and cycle performance with respect to graphite electrodes [10]. In the last few years, the $\mathrm{Sb}_{2} \mathrm{Se}_{3}$ nanostructured materials have been synthesized by other various techniques such as solvothermal process [11]. Recently, Kwon et al. prepared one-dimensional $\mathrm{Sb}_{2} \mathrm{Se}_{3}$ by evaporating a stacked elemental layer $(\mathrm{Sb} / \mathrm{Sb}-\mathrm{Se} / \mathrm{Se})$ deposition and then an additional annealing treatment process removed excess Se elements [12]. Ma et al. adopted a template-free solvothermal route to obtain the large-scale single-crystalline $\mathrm{Sb}_{2} \mathrm{Se}_{3}$ nanowires [13]. Xue and $\mathrm{Fu}$ have researched $\mathrm{Sb}_{2} \mathrm{O}_{3}$ nanomaterials, which have the high reversible capacity of about $794 \mathrm{mAh} \mathrm{g}^{-1}$ and a relatively large irreversible capacity loss $\left(234 \mathrm{mAhg}^{-1}\right)$. Besides, Xue and $\mathrm{Fu}$ have also reported on a large reversible discharge capacity in $\mathrm{Sb}_{2} \mathrm{Se}_{3}$ thin films deposited by pulsed laser deposition for Li-ion batteries cycled between 0.3 and $2.5 \mathrm{~V}$. The capacity was found in the range between 530.5 and $660.7 \mathrm{mAh} \mathrm{g}^{-1}$ during the first 100 cycles. This indicates that the $\mathrm{Sb}_{2} \mathrm{Se}_{3}$ 


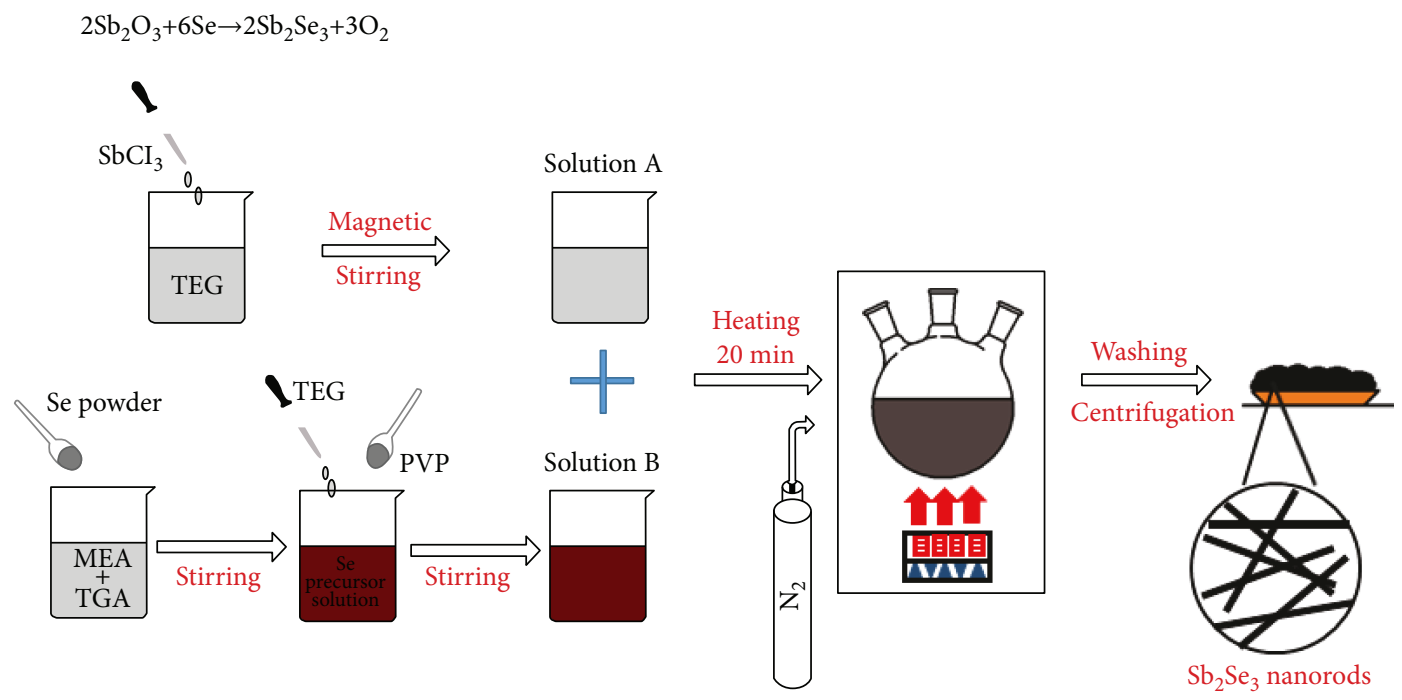

Scheme 1: Sketch diagram of preparing $\mathrm{Sb}_{2} \mathrm{Se}_{3}$ nanorods.

anode material has high reversible capacity in Li-ion batteries [14]. However, the loading charge in $\mathrm{Sb}_{2} \mathrm{Se}_{3}$ thin films is very low and its alloying combination reaction is associated with a drastic volume expansion upon lithiation, thus usually resulting in the active material pulverization and falling out from the collector, finally leading to the marked decrease of the long-term cycle performance. In addition, the pulsed laser deposition method is not compatible with low-cost fabrication. It is commonly agreed now that by using nanostructured electrode materials having particular dimension-related effects and large specific surface area can greatly relieve the volume expansion following the Li-alloying reaction. Therefore, the $\mathrm{Sb}_{2} \mathrm{Se}_{3}$ nanostructured composite material has been investigated showing excellent electrochemical properties in this paper, such as long cycle stability, good initial coulombic efficiency, and high energy density. In order to investigate the improved electrochemical properties of $\mathrm{Sb}_{2} \mathrm{Se}_{3}$ nanostructured materials, we report on a new low-cost fabrication method to dissolve the Se powder based on the mixed solvents of monoethanolamine and thioglycolic acid at room temperature in air for the first time [15].

\section{Experimental}

As shown in Scheme 1, $1 \mathrm{mmol}$ antimony trichloride $\left(\mathrm{SbCl}_{3}\right.$, 99.9\%, Aladdin) was dissolved in $20 \mathrm{~mL}$ triethylene glycol (TEG, 99\%, Aladdin) with magnetic stirring at room temperature for $2 \mathrm{~h}$ to get a clear cationic solution. $3 \mathrm{mmol}$ Se powder was immediately dissolved in $2.7 \mathrm{~mL}$ monoethanolamine (MEA, 99\%, Aladdin) and $0.3 \mathrm{~mL}$ thioglycolic acid (TGA, $80 \%$, Aladdin) after stirring at room temperature to get a brownish red Se precursor solution. $80 \mathrm{~mL}$ TEG with $0.2 \mathrm{~g}$ PVP in a three-necked flask was installed in a heating mantle through magnetic stirring and attached to a Schlenk line. The three-necked flask was degassing and flowing nitrogen alternately for three times at room temperature. Then, the Se precursor solution was injected into the flask and stirred for 30 min under nitrogen flow. Then, the three-necked flask was heated to $210^{\circ} \mathrm{C}$. Meanwhile, $10 \mathrm{~mL}$ cationic solution was swiftly injected into the flask and kept for $20 \mathrm{~min}$ at the same temperature. Afterward, the reaction solution was cooled to room temperature and precipitated by high-speed centrifugation. The precipitation was washed ultrasonically with excess amounts of absolute ethanol $\left(\mathrm{CH}_{3} \mathrm{CH}_{2} \mathrm{OH}\right.$, $99.7 \%$, Aladdin) followed by centrifugation for 4 times in order to purify the thick $\mathrm{Sb}_{2} \mathrm{Se}_{3}$ nanorods. In addition, we found that it is possible to control the size of nanorods by adjusting the heating temperature of the three-necked flask. The three-necked flask with a mixture of Se precursor solution and cationic solution was heated at $180^{\circ} \mathrm{C}$ for $20 \mathrm{~min}$ and then proceed on to the next steps, such as nature cooling, centrifugation, and washing. We eventually obtained the tiny $\mathrm{Sb}_{2} \mathrm{Se}_{3}$ nanorods. The purified products were used for further characterization. The chemical equations associated with the preparation of $\mathrm{Sb}_{2} \mathrm{Se}_{3}$ are as follows:

$$
\begin{aligned}
2 \mathrm{SbCl}_{3}+3 \mathrm{H}_{2} \mathrm{O} & \rightarrow \mathrm{Sb}_{2} \mathrm{O}_{3}+6 \mathrm{HCl} \\
2 \mathrm{Sb}_{2} \mathrm{O}_{3}+6 \mathrm{Se} & \rightarrow 2 \mathrm{Sb}_{2} \mathrm{Se}_{3}+3 \mathrm{O}_{2}
\end{aligned}
$$

The crystal structural characterizations were carried out by X-ray diffraction (XRD, D8 Advance, Bruker) using $\mathrm{Cu}$ $\mathrm{K} \alpha$ radiation $(\lambda=0.1542 \mathrm{~nm})$. The surface morphologies and microstructure were characterized by scanning electron microscopy (SEM, JSM-6700F, JOEL) and transmission electron microscopy (TEM, JEM-2100F, JOEL), respectively.

The electrochemical performance was investigated using coin-type cells (CR2025), in which the $\mathrm{Sb}_{2} \mathrm{Se}_{3}$ nanorods were used as a working electrode and lithium foil was used as the counter and reference electrode. The electrolyte was $1 \mathrm{~mol} \mathrm{dm}^{-3} \mathrm{LiPF}_{6}$ dissolved in a mixture of ethylene carbonate/diethyl carbonate/dimethyl carbonate (EC/DEC/DMC) with a volume ratio of $1: 1: 1$, and the separator was microporous polypropylene film. The $\mathrm{Sb}_{2} \mathrm{Se}_{3}$ electrode was prepared by mixing $80 \mathrm{wt} \%$ of as-prepared dispersed $\mathrm{Sb}_{2} \mathrm{Se}_{3}$ nanorods, $10 \mathrm{wt} \%$ polyvinylidene fluoride (PVDF, Kynar, 


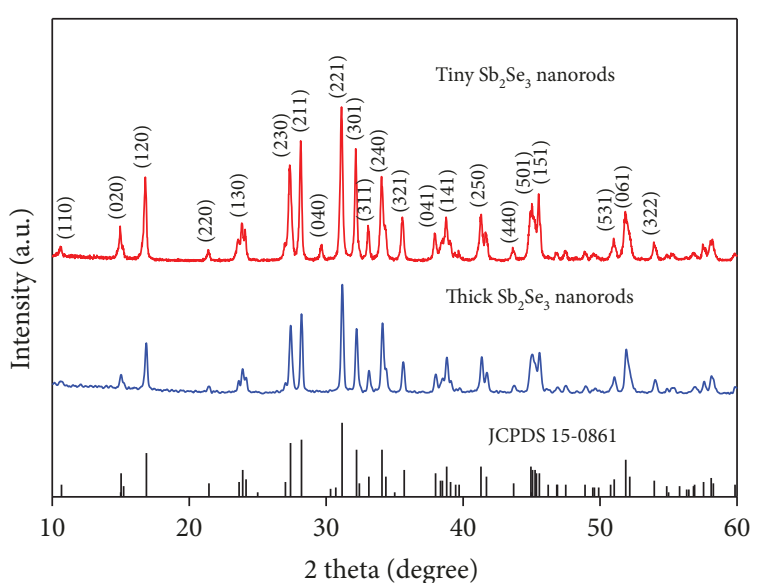

FIGURE 1: XRD patterns of the thick $\mathrm{Sb}_{2} \mathrm{Se}_{3}$ and the tiny $\mathrm{Sb}_{2} \mathrm{Se}_{3}$ nanorods.

HSV900) as a binder, and $10 \mathrm{wt} \%$ acetylene black (MTI, 99.5\% purity) conducting agent in 1-methyl-2-pyrrolidinone (NMP, Sigma-Aldrich, $\geq 99.5 \%$ purity). The resulting slurry was uniformly spread on a $\mathrm{Cu}$ foil using a doctor blade to obtain electrode material thickness about $15 \mu \mathrm{m}$ and dried at $60^{\circ} \mathrm{C}$ for $12 \mathrm{~h}$. The resulting electrode film was cut into circular disks with $1.5 \mathrm{~cm}$ diameter. The active material loading amount of each electrode sheet is approximately $3 \mathrm{mg} \mathrm{cm}^{-2}$. The coin cells were assembled in high-purity argon- (99.9995\%, purity) filled glove box (MBraun) and tested galvanostatically on a multichannel battery tester (BT-2000, Arbin Instruments) in a cut-off potential window from 0.01 to $3.0 \mathrm{~V}$ vs. $\mathrm{Li}^{+} / \mathrm{Li}$ at different current densities.

\section{Results and Discussion}

Figure 1 shows the XRD patterns of the tiny $\mathrm{Sb}_{2} \mathrm{Se}_{3}$ and thick $\mathrm{Sb}_{2} \mathrm{Se}_{3}$ nanorods. We could clearly index all the diffraction peaks with the orthorhombic phase of $\mathrm{Sb}_{2} \mathrm{Se}_{3}$ with space group of $\mathrm{Pbnm}$ (62), in good agreement with the standard JCPDS card no. 15-0861. Interestingly, no impurity phases are found in the diffraction pattern. Compared with the thick $\mathrm{Sb}_{2} \mathrm{Se}_{3}$, the tiny $\mathrm{Sb}_{2} \mathrm{Se}_{3}$ nanorods exhibit the stronger diffractions (110) and (040), which indicates the enhanced crystallinity of the tiny $\mathrm{Sb}_{2} \mathrm{Se}_{3}$ nanorods.

Raman spectroscopy is used to further analyze the structure of the crystalline thick $\mathrm{Sb}_{2} \mathrm{Se}_{3}$ and tiny $\mathrm{Sb}_{2} \mathrm{Se}_{3}$ nanorods. Both of the spectrum in Figure 2 are detected at $83,118,189,252,356,373$, and $450 \mathrm{~cm}^{-1}$, respectively, implying that the existence of the pure $\mathrm{Sb}_{2} \mathrm{Se}_{3}$ phase [16]. Compared with the thick $\mathrm{Sb}_{2} \mathrm{Se}_{3}$ nanorods, the greater peak intensity with the tiny $\mathrm{Sb}_{2} \mathrm{Se}_{3}$ nanorods indicates the enhancement of crystallinity.

XPS data are carried out to verify the chemical components and the valence states of elements in the $\mathrm{Sb}_{2} \mathrm{Se}_{3}$ nanorods. Figure 3(a) reveals two obvious high intensity $\mathrm{Sb}$ peaks at around $3 \mathrm{~d}_{3 / 2}(537.87 \mathrm{eV})$ and $3 \mathrm{~d}_{5 / 2}(528.47 \mathrm{eV})$, which are ascribed to the charge state of $\mathrm{Sb}^{3+}$ [17]. In addition, the other two relative weak Sb peak at around $3 \mathrm{~d}_{3 / 2}$ $(539.15 \mathrm{eV})$ and $3 \mathrm{~d}_{5 / 2}(529.78 \mathrm{eV})$, implying the oxidation

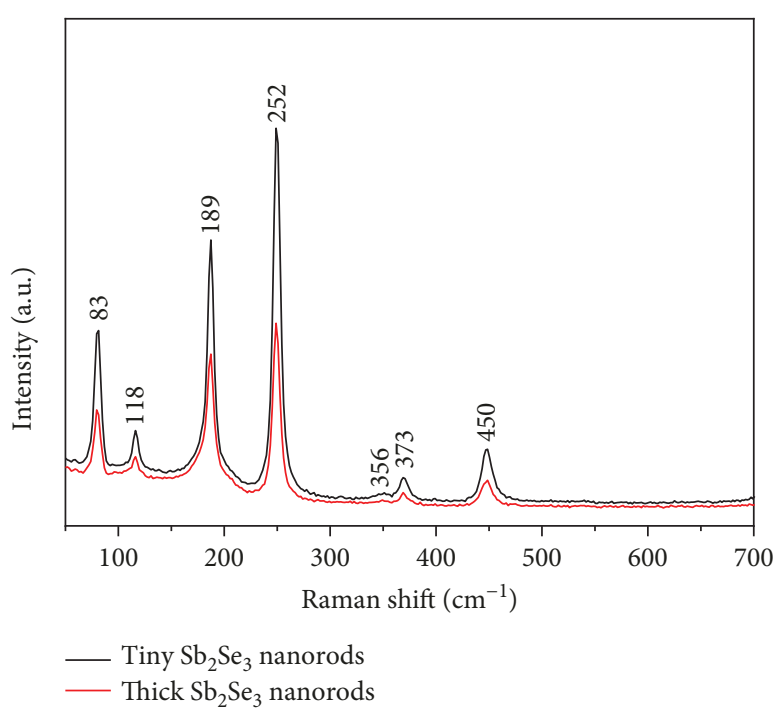

FIgURE 2: Raman spectrums of the thick $\mathrm{Sb}_{2} \mathrm{Se}_{3}$ and the tiny $\mathrm{Sb}_{2} \mathrm{Se}_{3}$ nanorods.

of the surfaces for $\mathrm{Sb}_{2} \mathrm{Se}_{3}$ nanorods although $\mathrm{Sb}_{2} \mathrm{O}_{3}$ is not detected by XRD and Raman results [18]. The XPS data for the valence state of $\mathrm{Se}^{2-}$ is split into $3 \mathrm{~d}_{3 / 2}(53.81 \mathrm{eV})$ and $3 d_{5 / 2}(53.01 \mathrm{eV})$ in Figure 3(b) [17]. Both of the thick $\mathrm{Sb}_{2} \mathrm{Se}_{3}$ and tiny $\mathrm{Sb}_{2} \mathrm{Se}_{3}$ nanorods with $\mathrm{Sb}^{3+}$ and $\mathrm{Se}^{2-}$ states prove the purity of $\mathrm{Sb}_{2} \mathrm{Se}_{3}$ phase.

High-resolution transmission and scanning electronic microscopy (HR-TEM and SEM) images from the thick $\mathrm{Sb}_{2} \mathrm{Se}_{3}$ and tiny $\mathrm{Sb}_{2} \mathrm{Se}_{3}$ nanorods are shown in Figures 4 and 5, respectively. The images show the diameter distribution histograms of the $\mathrm{Sb}_{2} \mathrm{Se}_{3}$ nanorods obtained from SEM data. As shown in Figures 4(a)-4(c), the arrangement of thick $\mathrm{Sb}_{2} \mathrm{Se}_{3}$ nanorods is relatively disordered and the average diameter of nanorods has already exceeded the value of $90 \mathrm{~nm}$. However, the other $\mathrm{Sb}_{2} \mathrm{Se}_{3}$ nanorods are welldispersed, tiny, and smooth with an average diameter ranging from 6 to $8 \mathrm{~nm}$ in Figures 5(a)-5(c). The analysis on HR-TEM images provides further insights on the $\mathrm{Sb}_{2} \mathrm{Se}_{3}$ nanostructure: both Figures 4(d) and 5(d) show the presence of lattice fringes with a plane spacing of $0.525 \mathrm{~nm}$, corresponding to the (120) lattice plane of single-crystal $\mathrm{Sb}_{2} \mathrm{Se}_{3}$ nanorods. The result also indicates that the preferential growth direction of $\mathrm{Sb}_{2} \mathrm{Se}_{3}$ nanorods is along the [120] crystal orientation. Consistent with the XRD, Raman, XPS, $\mathrm{SEM}$, and TEM results, the tiny $\mathrm{Sb}_{2} \mathrm{Se}_{3}$ nanorods deliver a well-crystallized form. The EDS mapping of the tiny $\mathrm{Sb}_{2} \mathrm{Se}_{3}$ nanorods shown in Figure 6 indicates a uniform distribution of $\mathrm{Sb}$ and Se throughout the tiny $\mathrm{Sb}_{2} \mathrm{Se}_{3}$ nanorods.

The electrochemical performance of thick $\mathrm{Sb}_{2} \mathrm{Se}_{3}$ and tiny $\mathrm{Sb}_{2} \mathrm{Se}_{3}$ nanorod electrodes was investigated in a LIB cell assembly with lithium metal acting as the counter and reference electrode. Figures 7(a) and 7(b) showed the galvanostatic charge and discharge behavior obtained for the tiny $\mathrm{Sb}_{2} \mathrm{Se}_{3}$ nanorods, and the thick $\mathrm{Sb}_{2} \mathrm{Se}_{3}$ nanorods as working electrode were measured at a current density of $0.1 \mathrm{C}$ between 0.01 and $3 \mathrm{~V}$. As can be seen from Figure 7(a), all the discharge curves at the initial three cycles have two prolonged 


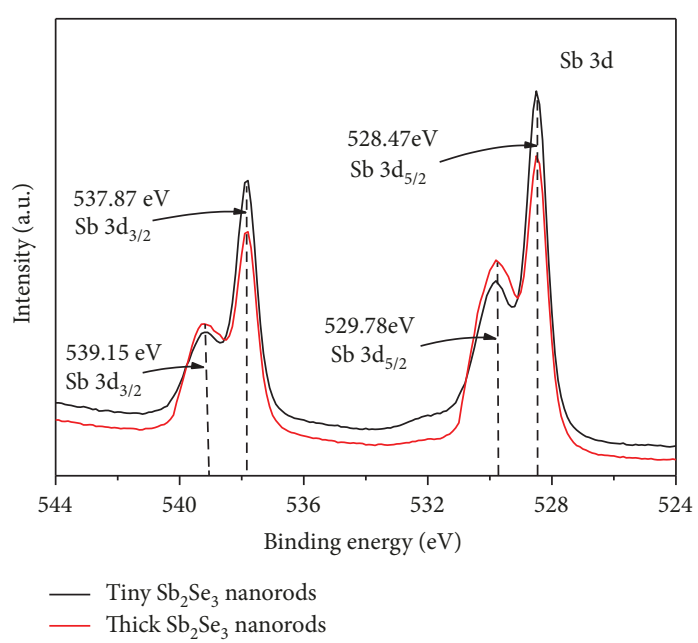

(a)

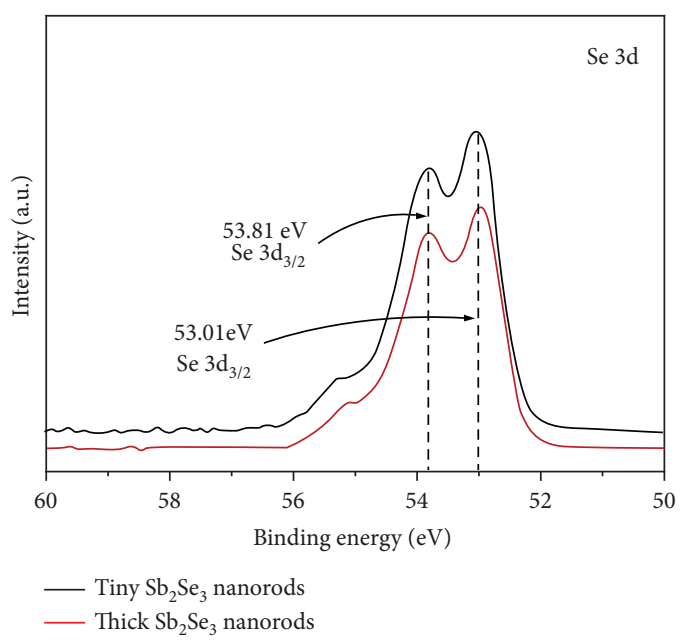

(b)

FIGURE 3: XPS data of (a) Sb 3d and (b) Se 3d for the thick $\mathrm{Sb}_{2} \mathrm{Se}_{3}$ and the tiny $\mathrm{Sb}_{2} \mathrm{Se}_{3}$ nanorods.

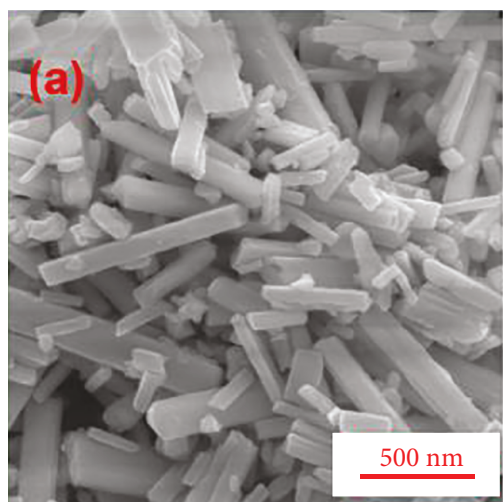

(a)

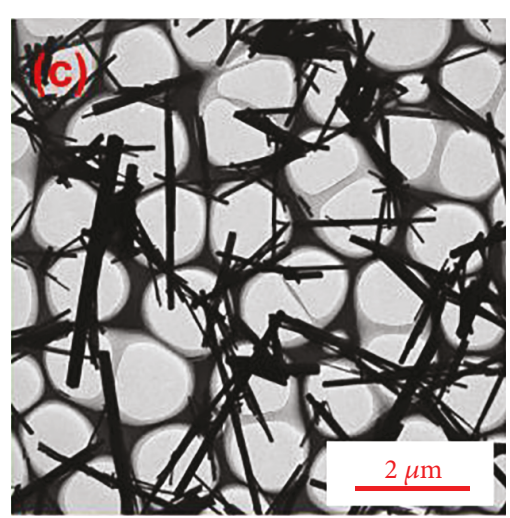

(c)

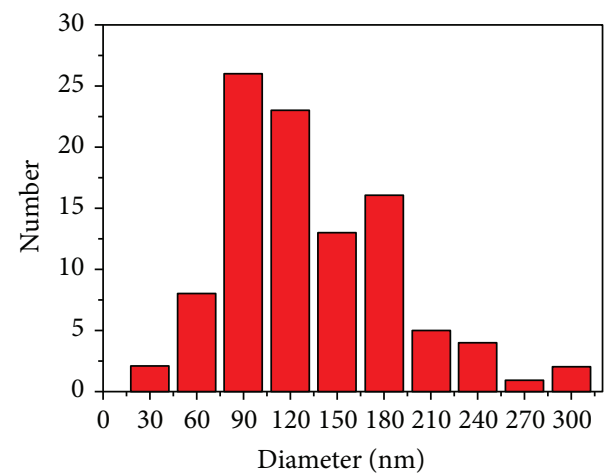

Diameter

(b)

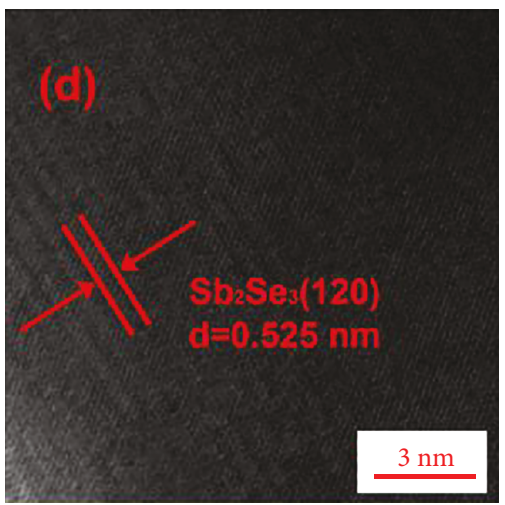

(d)

FIgURE 4: SEM image (a), diameter size histogram (b), TEM image (c), and HR-TEM image (d) of the thick $\mathrm{Sb}_{2} \mathrm{Se}_{3}$ nanorods.

plateaus at about $1.5 \mathrm{~V}$ and $0.9 \mathrm{~V}$, corresponding to the twostep reaction of reduction. The upper plateau at about $1.5 \mathrm{~V}$ is associated to the lithiation process of $\mathrm{Sb}_{2} \mathrm{Se}_{3}$ directly to $\mathrm{Sb}$ and $\mathrm{Li}_{2} \mathrm{Se}$ [19]. And the other plateau at about $0.9 \mathrm{~V}$ is attributed to the alloying reaction of metallic $\mathrm{Sb}$ to $\mathrm{Li}_{3} \mathrm{Sb}$ [20]. These results confirm the global reactions (2) and (3) based on the simple equations, which suggests that a lithium insertion could take place [21-23].

$$
\begin{gathered}
\mathrm{Sb}_{2} \mathrm{Se}_{3}+6 \mathrm{Li}^{+}+6 \mathrm{e}^{-} \rightarrow 2 \mathrm{Sb}+3 \mathrm{Li}_{2} \mathrm{Se} \\
6 \mathrm{Li}^{+}+2 \mathrm{Sb}+6 \mathrm{e}^{-} \rightarrow 2 \mathrm{Li}_{3} \mathrm{Sb}
\end{gathered}
$$




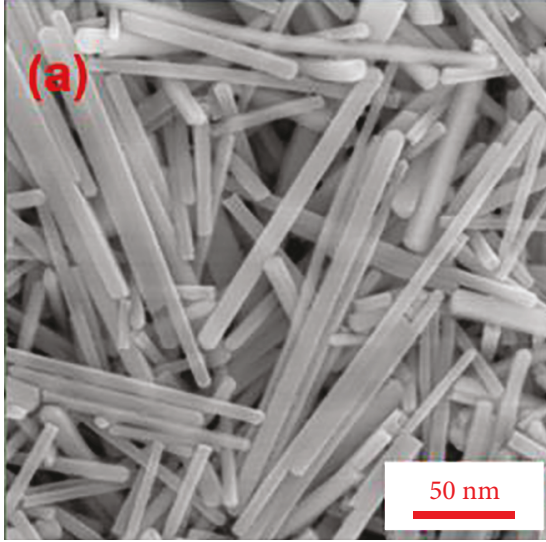

(a)

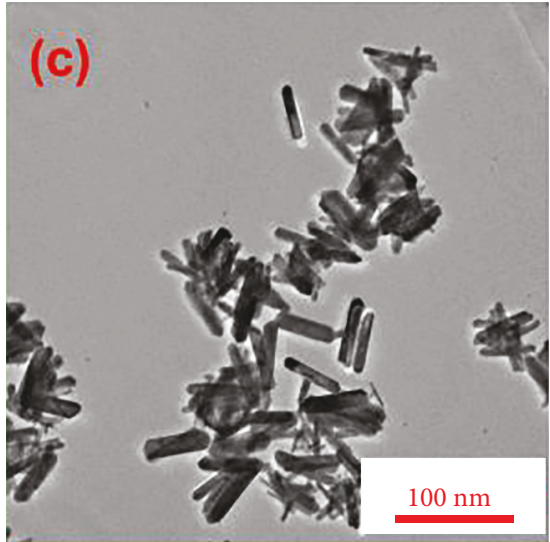

(c)

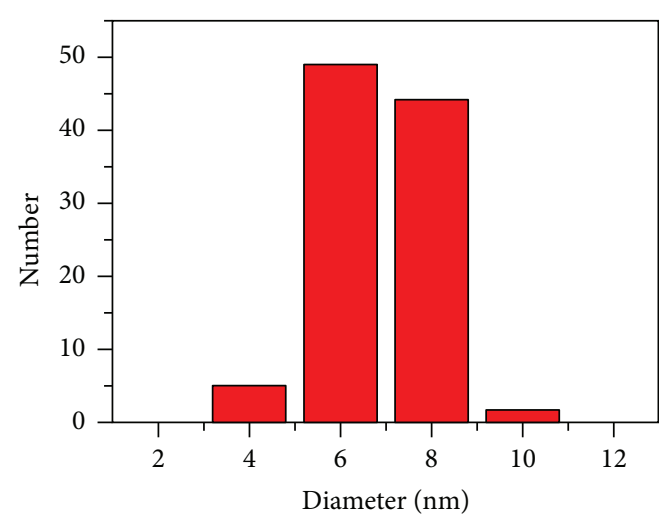

(b)

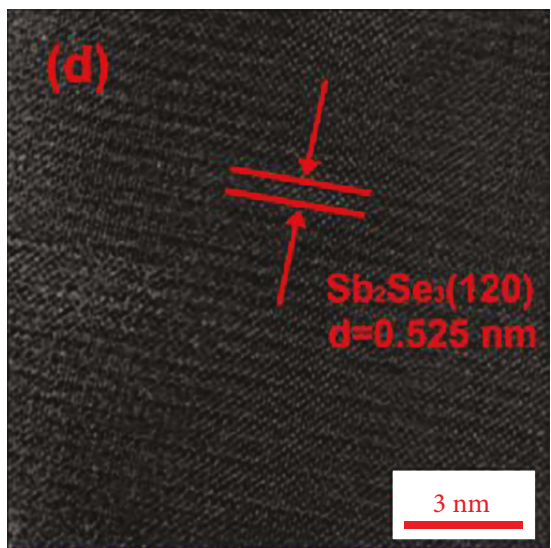

(d)

Figure 5: SEM image (a), diameter size histogram (b), TEM image (c), and HR-TEM image (d) of the tiny $\mathrm{Sb}_{2} \mathrm{Se}_{3}$ nanorods.
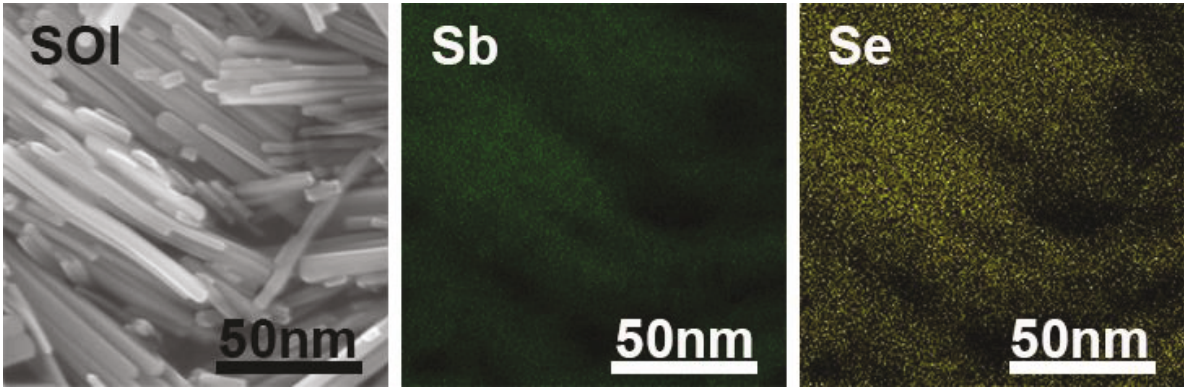

FIGURE 6: EDS mapping showing the distribution of $\mathrm{Sb}$ and $\mathrm{Se}$ of the tiny $\mathrm{Sb}_{2} \mathrm{Se}_{3}$ nanorods.

Besides, the plateaus in the charge curves are ascribed to the multistep oxidative transformation of $\mathrm{Li}_{3} \mathrm{Sb}$ associated with the formation of $\mathrm{Sb}_{2} \mathrm{Se}_{3}$ [24]. The discharge capacities of thick $\mathrm{Sb}_{2} \mathrm{Se}_{3}$ nanorod electrode during the first three cycles are $634 \mathrm{mAh} \mathrm{g}^{-1}, 318 \mathrm{mAh} \mathrm{g}^{-1}$, and $280 \mathrm{mAh} \mathrm{g}^{-1}$, shown in Figure 7(b). However, the initial discharge and charge capacities of tiny $\mathrm{Sb}_{2} \mathrm{Se}_{3}$ nanorod electrode are around $702 \mathrm{mAh} \mathrm{g}^{-1}$ and $475 \mathrm{mAhg}^{-1}$, respectively, and the initial coulombic efficiency of the LIB is $67.7 \%$. The irreversible capacity may be attributed to the irreversible electrolyte decomposition and the inevitable formation of the SEI film on the electrode surface [25]. What is more, the welldefined voltage plateaus and potential positions remained almost unchanged during the subsequent cycles. This phenomenon suggests a good cycling stability of the tiny $\mathrm{Sb}_{2} \mathrm{Se}_{3}$ nanorod electrode in LIBs.

The cycling performance and coulombic efficiency of the tiny $\mathrm{Sb}_{2} \mathrm{Se}_{3}$ and the thick $\mathrm{Sb}_{2} \mathrm{Se}_{3}$ nanorod electrodes are compared in Figure 8. Indeed, the thick $\mathrm{Sb}_{2} \mathrm{Se}_{3}$ nanorod electrode only shows a discharge capacity of $48 \mathrm{mAh} \mathrm{g}^{-1}$ after 50 cycles at $0.1 \mathrm{C}$. However, a reversible capacity of the tiny $\mathrm{Sb}_{2} \mathrm{Se}_{3}$ nanorods is still $230 \mathrm{mAh} \mathrm{g}^{-1}$, indicating a much higher capacity retention after 100 cycles at $0.1 \mathrm{C}$. In addition, the coulombic efficiency increases significantly during the first five cycles and stabilizes around $99 \%$ in the subsequent cycles. Compared with the tiny $\mathrm{Sb}_{2} \mathrm{Se}_{3}$ nanorod electrodes, 


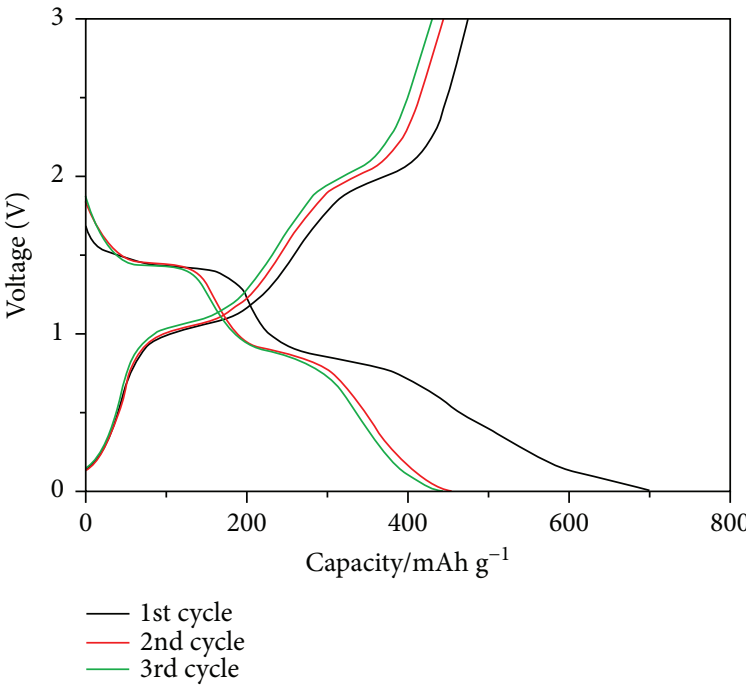

(a)

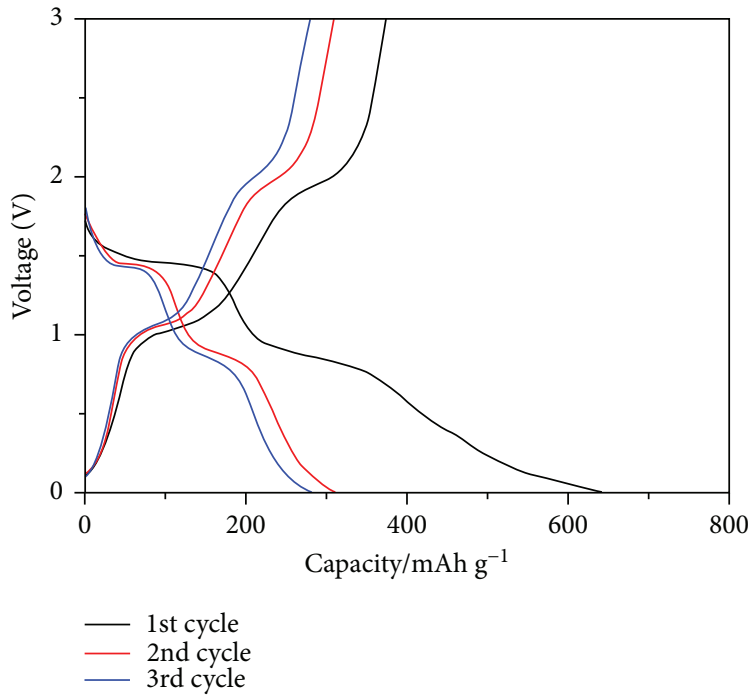

(b)

FIGURE 7: Galvanostatic charge and discharge profiles of (a) tiny $\mathrm{Sb}_{2} \mathrm{Se}_{3}$ nanorods and (b) thick $\mathrm{Sb}_{2} \mathrm{Se}_{3}$ nanorods as working electrodes in LIBs.

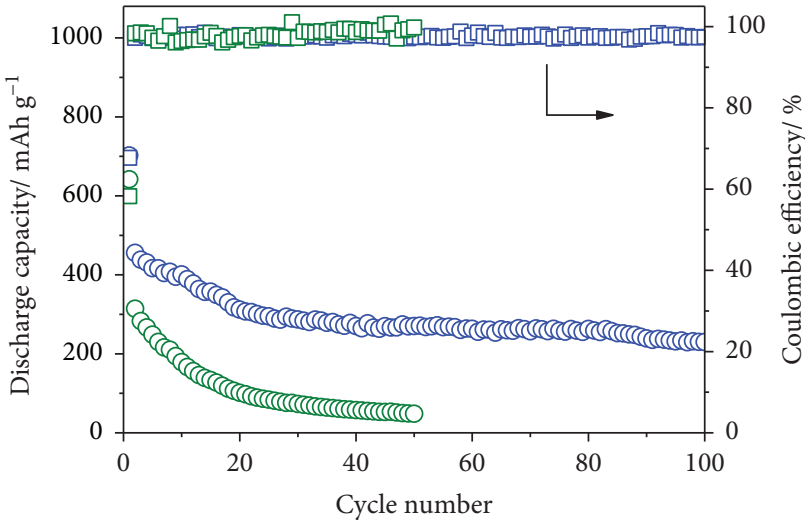

FIGURE 8: Cycling performance and corresponding coulombic efficiency of the thick $\mathrm{Sb}_{2} \mathrm{Se}_{3}$ nanorods (green) and tiny $\mathrm{Sb}_{2} \mathrm{Se}_{3}$ nanorods (blue) as working electrodes in LIBs.

the thick $\mathrm{Sb}_{2} \mathrm{Se}_{3}$ nanorod electrodes exhibit faster capacity fading and minimum reversible capacity because of the presence of different $\mathrm{Sb}_{2} \mathrm{Se}_{3}$ nanorod diameters. We can attribute the improved cycle stability to the pure one-dimensional $\mathrm{Sb}_{2} \mathrm{Se}_{3}$ nanostructure, which cannot only increase the contact area between the active materials and the electrolyte improving the utilization of $\mathrm{Sb}_{2} \mathrm{Se}_{3}$ nanorods but also decrease diffusion length of lithium ions. In addition, the one-dimensional nanostructure could relieve the intrinsic stress in Sb-based electrode materials, then slow the electrode pulverization upon cycling and enhance the capacity and cycling stability [26].

Figure 9 exhibits the rate performances of tiny $\mathrm{Sb}_{2} \mathrm{Se}_{3}$ nanorods and thick $\mathrm{Sb}_{2} \mathrm{Se}_{3}$ nanorods. As shown in Figure 9(a), after the first cycle at $0.1 \mathrm{C}$, the tiny $\mathrm{Sb}_{2} \mathrm{Se}_{3}$ nanorods have an average discharge capacity of $438 \mathrm{mAh} \mathrm{g}^{-1}$ at $0.1 \mathrm{C}$. With the increasing current rate, the capacity drops to $120 \mathrm{mAhg}^{-1}$ at $1 \mathrm{C}$. More importantly, the tiny $\mathrm{Sb}_{2} \mathrm{Se}_{3}$

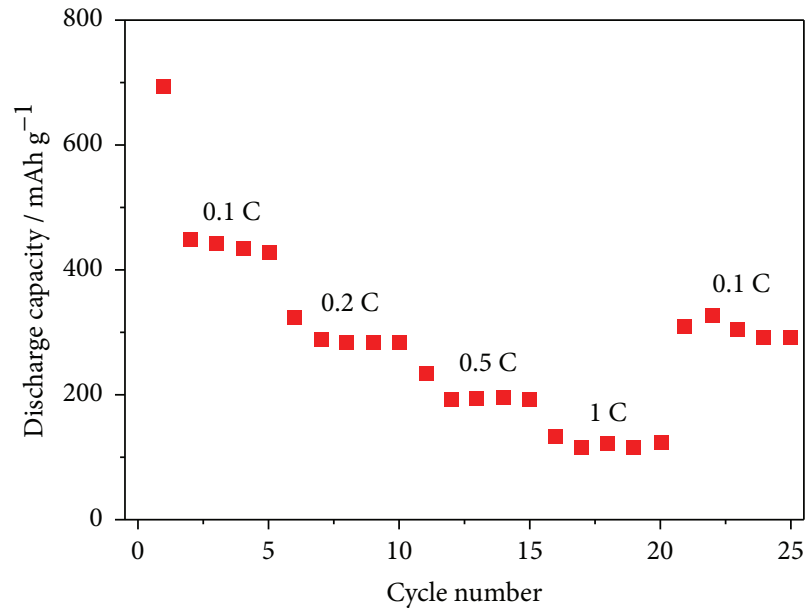

(a)

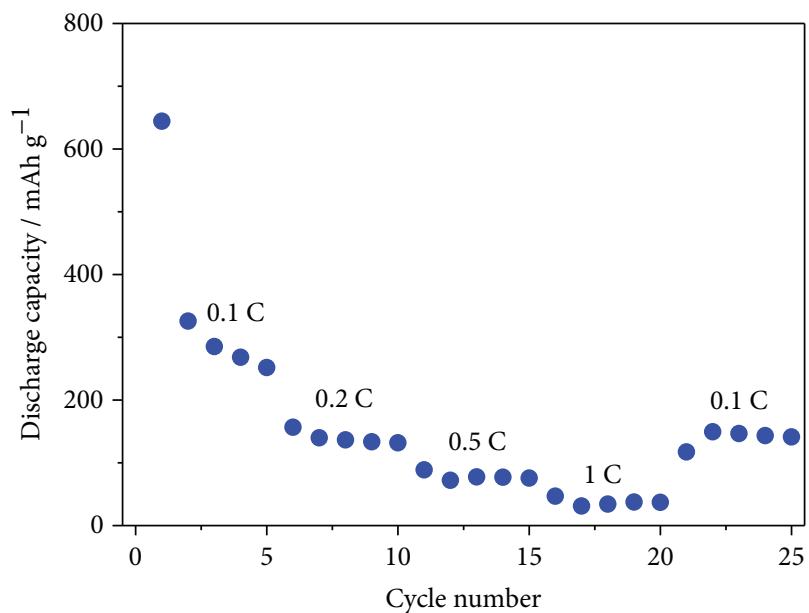

(b)

FIgURE 9: Rate performances of (a) tiny $\mathrm{Sb}_{2} \mathrm{Se}_{3}$ nanorods and (b) thick $\mathrm{Sb}_{2} \mathrm{Se}_{3}$ nanorods. 


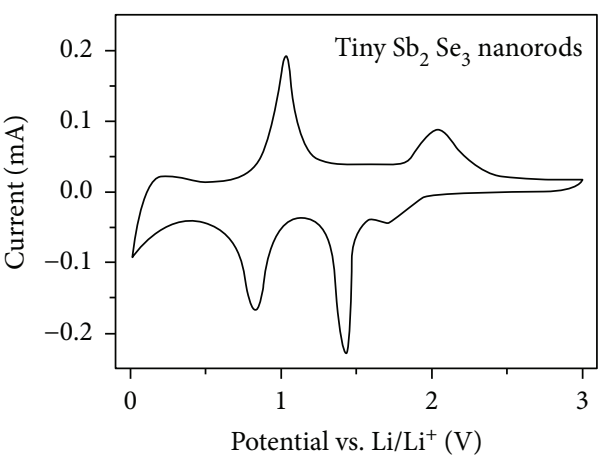

(a)

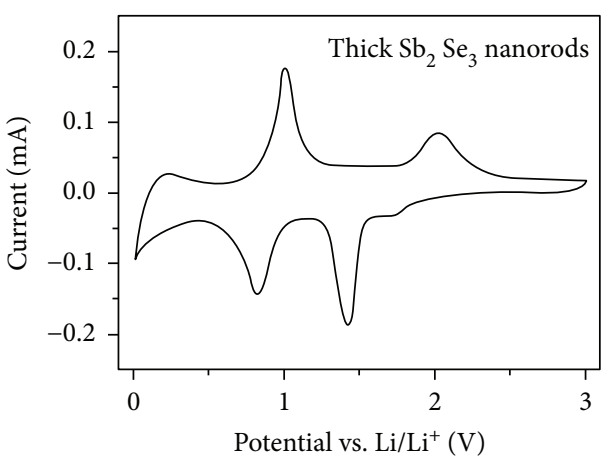

(b)

Figure 10: CV curves of (a) the tiny $\mathrm{Sb}_{2} \mathrm{Se}_{3}$ nanorods and (b) the thick $\mathrm{Sb}_{2} \mathrm{Se}_{3}$ nanorods.

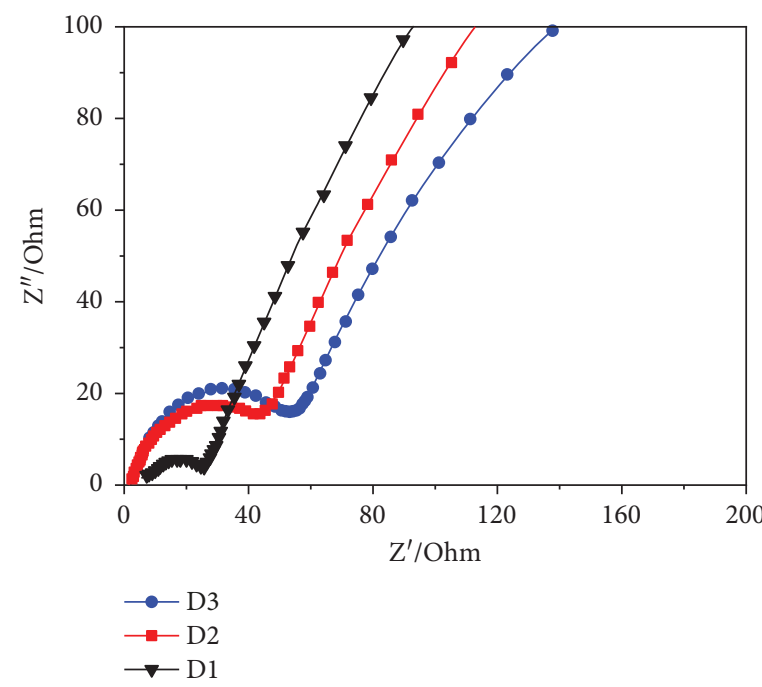

(a)

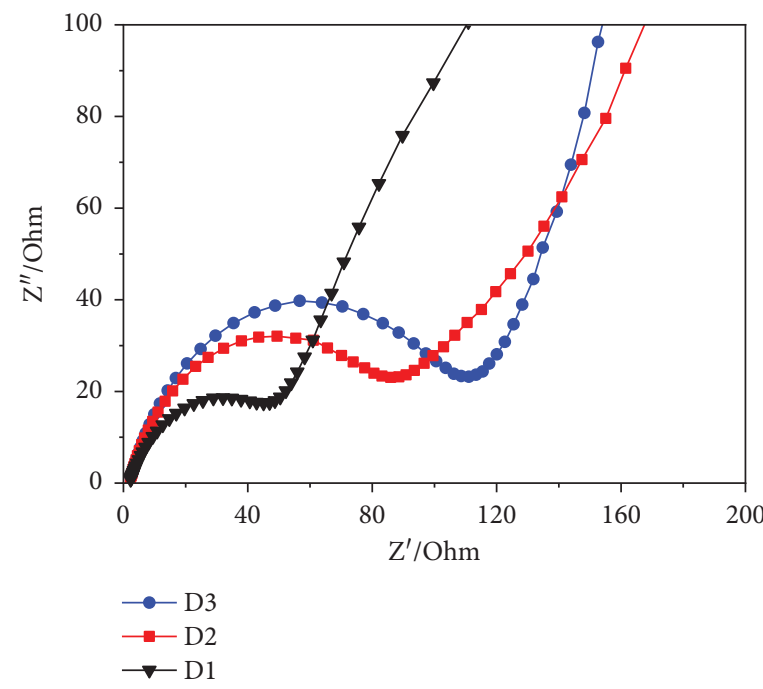

(b)

FIGURE 11: EIS plots of (a) the tiny $\mathrm{Sb}_{2} \mathrm{Se}_{3}$ nanorods and (b) the thick $\mathrm{Sb}_{2} \mathrm{Se}_{3}$ nanorods at different DODs.

nanorods can regain the reversible capacity of $304 \mathrm{mAh} \mathrm{g}^{-1}$, when the current rate returns back to $0.1 \mathrm{C}$. The thick $\mathrm{Sb}_{2} \mathrm{Se}_{3}$ nanorods present reversible capacities of 283, 140, 79, and $37 \mathrm{mAh} \mathrm{g}^{-1}$ at current rates of $0.1,0.2,0.5$, and $1 \mathrm{C}$, respectively. Hence, the tiny $\mathrm{Sb}_{2} \mathrm{Se}_{3}$ nanorods deliver a relative excellent rate performance.

Figure 10 shows the CV curves of (a) the tiny $\mathrm{Sb}_{2} \mathrm{Se}_{3}$ nanorods and (b) the thick $\mathrm{Sb}_{2} \mathrm{Se}_{3}$ nanorods between 0.01 and $3 \mathrm{~V}$ for the initial cycle at the scan rate of $0.1 \mathrm{mV} \mathrm{s}^{-1}$. Both of the CV curves have two redox pairs. Two cathodic peaks appears at around $1.42 \mathrm{~V}$ and $0.83 \mathrm{~V}$, which can be ascribed to the lithiation formation of $\mathrm{Sb}$ embedded in $\mathrm{Sb}_{2} \mathrm{Se}_{3}$ and the alloying transformation between metallic $\mathrm{Sb}$ and $\mathrm{Li}_{3} \mathrm{Sb}$, respectively [20]. In additional, the other obvious anodic peaks are located at about $1.01 \mathrm{~V}$ and $2.03 \mathrm{~V}$ corresponding to the dealloying transformation and delithiation transmission [24]. There is a tiny peak located at around $1.72 \mathrm{~V}$, which can be attributed to the formation of the SEI layers.

Electrochemical impedance spectroscopy (EIS) plots of the tiny $\mathrm{Sb}_{2} \mathrm{Se}_{3}$ and the thick $\mathrm{Sb}_{2} \mathrm{Se}_{3}$ nanorod electrodes are

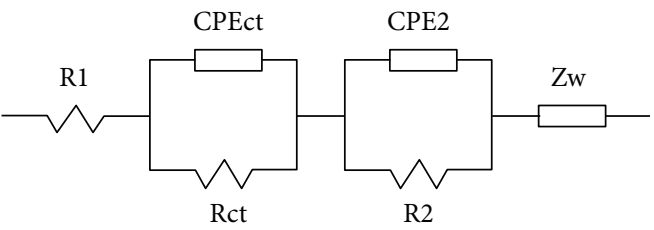

FIgURE 12: Equivalent circuit diagram of EIS.

at different depths of discharge (DODs). In Figure 11, D1, D2, and D3 represent relevant curves obtained at DODs of $0 \mathrm{mAh} \mathrm{g}^{-1}, 200 \mathrm{mAhg}^{-1}$, and full discharge in this study. Both of the Nyquist plots deliver a semicircle corresponding to the charge transfer resistance $\left(R_{\mathrm{ct}}\right)$ in the high-to-medium frequency and an inclined line of the Warburg impedance in the low frequency. The equivalent circuit of the discharge behavior for samples is shown in Figure 12. $R_{1}$ represents the Ohmic resistance, and $R_{\mathrm{ct}}$ and $R_{2}$ represent the charge transfer resistance and the resistance of the surface layer of $\mathrm{Sb}_{2} \mathrm{Se}_{3}$ in contact with the electrolyte, respectively. $\mathrm{CPE}_{\mathrm{ct}}$ and $\mathrm{CPE}_{2}$ are the double-layer capacitances, and $\mathrm{ZW}$ 


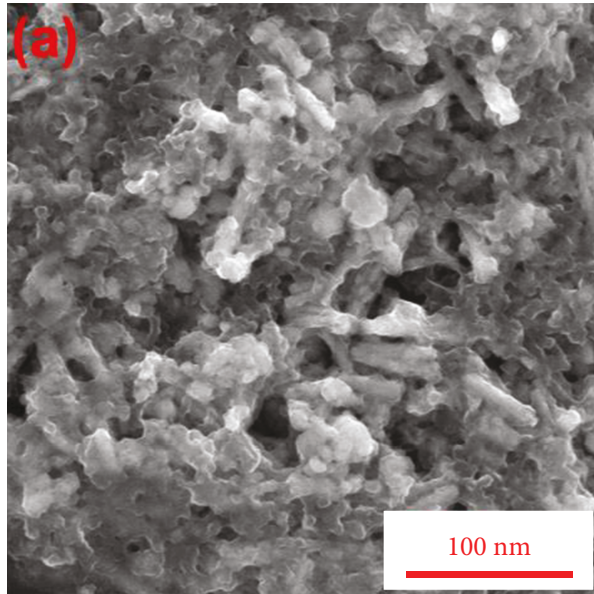

(a)

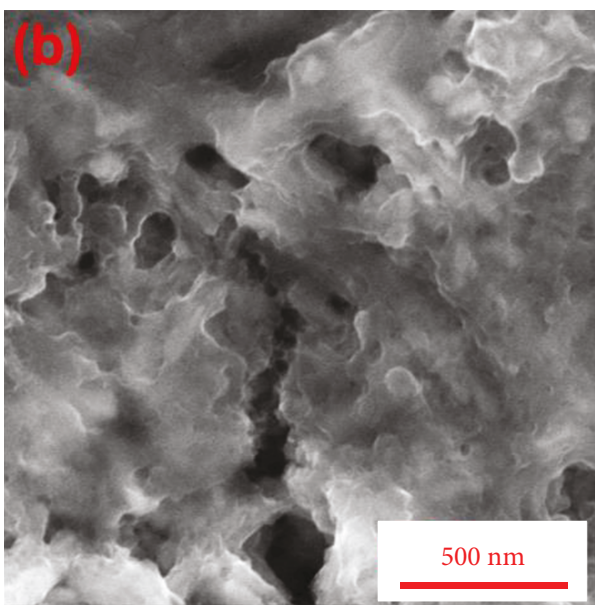

(b)

Figure 13: SEM images of (a) the tiny $\mathrm{Sb}_{2} \mathrm{Se}_{3}$ nanorods and (b) the thick $\mathrm{Sb}_{2} \mathrm{Se}_{3}$ nanorods after 50 charge/discharge cycles.

is the Warburg impedance. With the increase in DOD, the diameter of the semicircle becomes increasingly larger, indicating higher charge transfer resistance. Compared with the thick $\mathrm{Sb}_{2} \mathrm{Se}_{3}$ nanorods, the tiny $\mathrm{Sb}_{2} \mathrm{Se}_{3}$ nanorods all displayed lower charge transfer resistance throughout the whole discharge process, as indicated by their semicircles, which may contribute to the increase in the discharge capacity [27].

To further understand the mechanism of Li cycling, the electrode after 50 cycles was investigated by SEM images. As shown in Figure 13, both of the $\mathrm{Sb}_{2} \mathrm{Se}_{3}$ nanorod morphologies change after cycling, and a partial agglomeration of the active material was observed. Such change can negatively affect the battery performance due to separation of active substance from the conducting agent. The morphology and structure of the one-dimensional tiny $\mathrm{Sb}_{2} \mathrm{Se}_{3}$ nanorod structure were retained after cycling and indicate its structural stability upon electrochemical cycling in Figure 13(a). However, the thick $\mathrm{Sb}_{2} \mathrm{Se}_{3}$ nanorods are almost invisible in Figure 13(b). It is clear that the tiny $\mathrm{Sb}_{2} \mathrm{Se}_{3}$ nanorods deliver a favorable electrochemical performance with high reversible capacity and good cycling stability in LIBs.

\section{Conclusions}

In this study, a new and facile polyol process is reported preparing $\mathrm{Sb}_{2} \mathrm{Se}_{3}$ nanorods, with controlled sizes, applied as working electrode material for LIBs. Compared with the thick $\mathrm{Sb}_{2} \mathrm{Se}_{3}$ nanorods, the tiny $\mathrm{Sb}_{2} \mathrm{Se}_{3}$ nanorods demonstrate a favorable electrochemical performance with high reversible capacity and good cycling stability in LIBs. The high reversible capability of the $\mathrm{Sb}_{2} \mathrm{Se}_{3}$ nanorods is $230 \mathrm{mAh} \mathrm{g}^{-1}$ after 100 cycles at $0.1 \mathrm{C}$. This study provides insights and indications on how to develop $\mathrm{Sb}_{2} \mathrm{Se}_{3}$-based electrode materials for conversion alloying reactions for high-performance batteries.

\section{Data Availability}

The data used to support the findings of this study are available from the corresponding author upon request.

\section{Conflicts of Interest}

The authors declare that there is no conflict of interests regarding the publication of this paper.

\section{Acknowledgments}

This work was supported by the Program for the Outstanding Young Talents of Hebei Province and Guangdong Provincial Science and Technology Project (2017A050506009).

\section{References}

[1] M. Winter, J. O. Besenhard, M. E. Spahr, and P. Novák, "Insertion electrode materials for rechargeable lithium batteries," Advanced Materials, vol. 10, no. 10, pp. 725-763, 1998.

[2] Y. Zhang, Y. Li, H. Li, Y. Zhao, F. Yin, and Z. Bakenov, "Electrochemical performance of carbon-encapsulated $\mathrm{Fe}_{3} \mathrm{O}_{4}$ nanoparticles in lithium-ion batteries: morphology and particle size effects," Electrochimica Acta, vol. 216, pp. 475-483, 2016.

[3] P. Poizot, S. Laruelle, S. Grugeon, L. Dupont, and J. M. Tarascon, "Nano-sized transition-metal oxides as negativeelectrode materials for lithium-ion batteries," Nature, vol. 407, no. 6803, pp. 496-499, 2000.

[4] J. W. Choi and D. Aurbach, "Promise and reality of postlithium-ion batteries with high energy densities," Nature Reviews Materials, vol. 1, no. 4, pp. 16013-16028, 2016.

[5] X. Wang, L. Huang, Y. Zhao, Y. Zhang, and G. Zhou, "Synthesis of mesoporous $\mathrm{ZnO}$ nanosheets via facile solvothermal method as the anode materials for lithium-ion batteries," Nanoscale Research Letters, vol. 11, no. 1, p. 37, 2016.

[6] H. Li, Y. Wei, Y. Zhang et al., "In situ sol-gel synthesis of ultrafine $\mathrm{ZnO}$ nanocrystals anchored on graphene as anode material for lithium-ion batteries," Ceramics International, vol. 42, no. 10, pp. 12371-12377, 2016.

[7] Y. Zhang, Y. Wei, H. Li, Y. Zhao, F. Yin, and X. Wang, "Simple fabrication of free-standing $\mathrm{ZnO} /$ graphene/carbon nanotube composite anode for lithium-ion batteries," Materials Letters, vol. 184, pp. 235-238, 2016.

[8] R. Xu, J. Lu, and K. Amine, "Progress in mechanistic understanding and characterization techniques of Li-S batteries," 
Advanced Energy Materials, vol. 5, no. 16, article 1500408, 2015.

[9] Z. W. Seh, Y. Sun, Q. Zhang, and Y. Cui, "Designing highenergy lithium-sulfur batteries," Chemical Society Reviews, vol. 45, no. 20, pp. 5605-5634, 2016.

[10] M. Z. Xue and Z. W. Fu, "Electrochemical reaction of lithium with nanostructured thin film of antimony trioxide," Electrochemistry Communications, vol. 8, no. 8, pp. 1250-1256, 2006.

[11] J. Lu, Q. Han, X. Yang, L. Lu, and X. Wang, "Preparation of ultra-long $\mathrm{Sb}_{2} \mathrm{Se}_{3}$ nanoribbons via a short-time solvothermal process," Materials Letters, vol. 62, no. 16, pp. 2415-2418, 2008.

[12] Y. H. Kwon, M. Jeong, H. W. Do, J. Y. Lee, and H. K. Cho, "Liquid-solid spinodal decomposition mediated synthesis of $\mathrm{Sb}_{2} \mathrm{Se}_{3}$ nanowires and their photoelectric behavior," Nanoscale, vol. 7, no. 30, pp. 12913-12920, 2015.

[13] J. Ma, Y. Wang, Y. Wang et al., "One-dimensional $\mathrm{Sb}_{2} \mathrm{Se}_{3}$ nanostructures: solvothermal synthesis, growth mechanism, optical and electrochemical properties," CrystEngComm, vol. 13, no. 7, pp. 2369-2374, 2011.

[14] M. Z. Xue and Z. W. Fu, "Pulsed laser deposited $\mathrm{Sb}_{2} \mathrm{Se}_{3}$ anode for lithium-ion batteries," Journal of Alloys and Compounds, vol. 458, no. 1-2, pp. 351-356, 2008.

[15] H. Liu, J. Zhang, X. Zheng et al., "Polyol process synthesis of metal selenide nanomaterials and their photovoltaic application," CrystEngComm, vol. 18, no. 36, pp. 6860-6866, 2016.

[16] J. Yang, Y. Lai, Y. Fan et al., "Photoelectrochemically deposited $\mathrm{Sb}_{2} \mathrm{Se}_{3}$ thin films: deposition mechanism and characterization," RSC Advances, vol. 5, no. 104, pp. 85592-85597, 2015.

[17] R. Jin, Z. Liu, L. Yang, J. Liu, Y. Xu, and G. Li, "Facile synthesis of sulfur doped $\mathrm{Sb}_{2} \mathrm{Se}_{3}$ nanosheets with enhanced electrochemical performance," Journal of Alloys and Compounds, vol. 579, pp. 209-217, 2013.

[18] W. E. Morgan, W. J. Stec, and J. R. Van Wazer, "Inner-orbital binding-energy shifts of antimony and bismuth compounds," Inorganic Chemistry, vol. 12, no. 4, pp. 953-955, 1973.

[19] D. Y. W. Yu, H. E. Hoster, and S. K. Batabyal, "Bulk antimony sulfide with excellent cycle stability as next-generation anode for lithium-ion batteries," Scientific Reports, vol. 4, no. 1, p. 4562, 2014.

[20] Z. Yi, Q. Han, Y. Cheng, Y. Wu, and L. Wang, "Facile synthesis of symmetric bundle-like $\mathrm{Sb}_{2} \mathrm{~S}_{3}$ micron-structures and their application in lithium-ion battery anodes," Chemical Communications, vol. 52, no. 49, pp. 7691-7694, 2016.

[21] L. Aldon, A. Garcia, J. Olivier-Fourcade et al., "Lithium insertion mechanism in Sb-based electrode materials from ${ }^{121} \mathrm{Sb}$ Mössbauer spectrometry," Journal of Power Sources, vol. 119-121, pp. 585-590, 2003.

[22] F. J. Fernández-Madrigal, P. Lavela, C. Pérez-Vicente, and J. L. Tirado, "Electrochemical reactions of polycrystalline $\mathrm{CrSb}_{2}$ in lithium batteries," Journal of Electroanalytical Chemistry, vol. 501, no. 1-2, pp. 205-209, 2001.

[23] R. Alcántara, F. J. Fernández-Madrigal, P. Lavela, J. L. Tirado, J. C. Jumas, and J. Olivier-Fourcade, "Electrochemical reaction of lithium with the $\mathrm{CoSb}_{3}$ skutterudite," Journal of Materials Chemistry, vol. 9, no. 10, pp. 2517-2521, 1999.

[24] P. V. Prikhodchenko, J. Gun, S. Sladkevich et al., "Conversion of hydroperoxoantimonate coated graphenes to $\mathrm{Sb}_{2} \mathrm{~S}_{3} @$ graphene for a superior lithium battery anode," Chemistry of Materials, vol. 24, no. 24, pp. 4750-4757, 2012.
[25] H. Jiang, Y. Hu, S. Guo, C. Yan, P. S. Lee, and C. Li, "Rational design of $\mathrm{MnO} /$ carbon nanopeapods with internal void space for high-rate and long-life Li-ion batteries," ACS Nano, vol. 8, no. 6, pp. 6038-6046, 2014.

[26] N. Wang, Z. Bai, Y. Qian, and J. Yang, "Double-walled $\mathrm{Sb} \mathrm{TiO}_{2-\mathrm{x}}$ nanotubes as a superior high-rate and ultralonglifespan anode material for Na-ion and Li-ion batteries," Advanced Materials, vol. 28, no. 21, pp. 4126-4133, 2016.

[27] J. Zeng, S. Wang, Q. Liu, and X. Lei, "High-capacity V-/Sc-/Tidoped $\mathrm{MnO}_{2}$ for $\mathrm{Li} / \mathrm{MnO}_{2}$ batteries and structural changes at different discharge depths," Electrochimica Acta, vol. 127, pp. 115-122, 2014. 


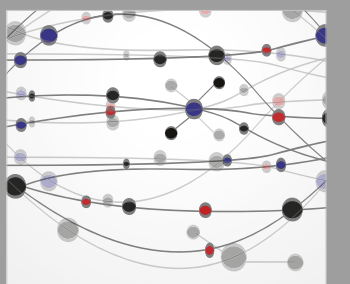

The Scientific World Journal
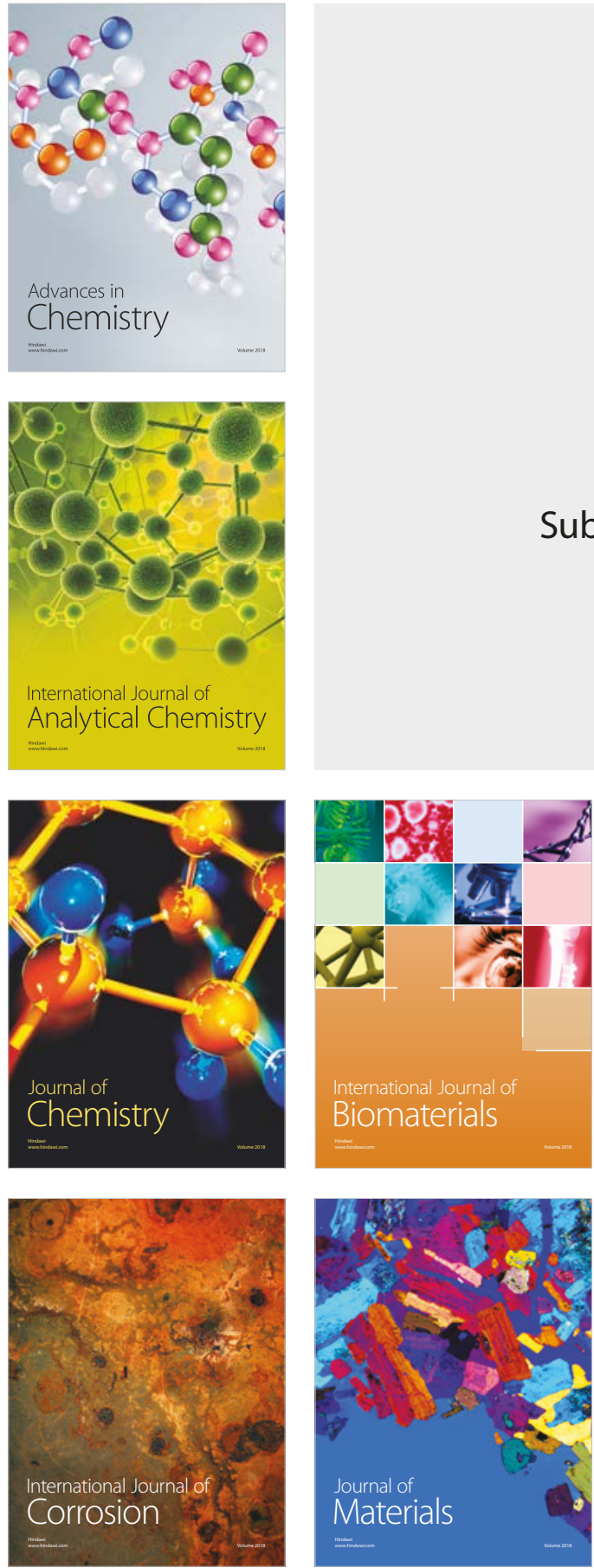

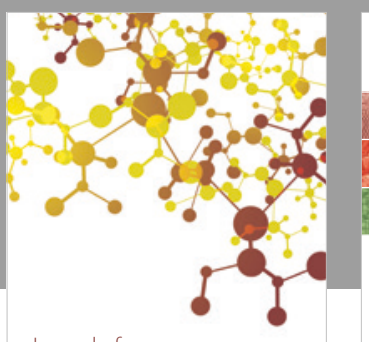

Journal of

Applied Chemistry
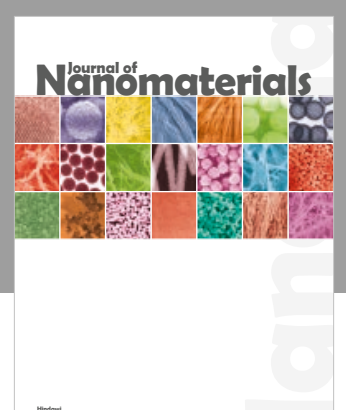

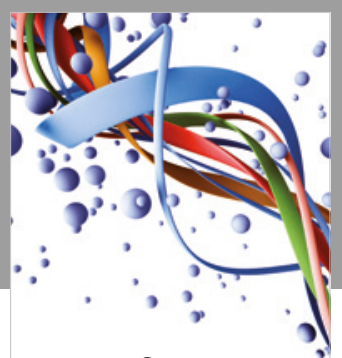

Scientifica

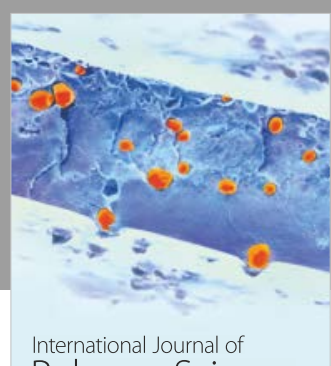

Polymer Science

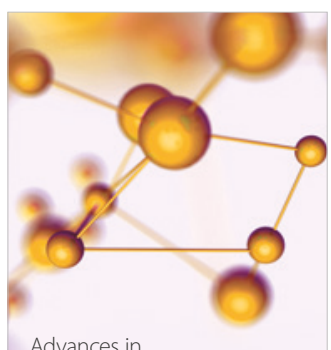

Physical Chemistry
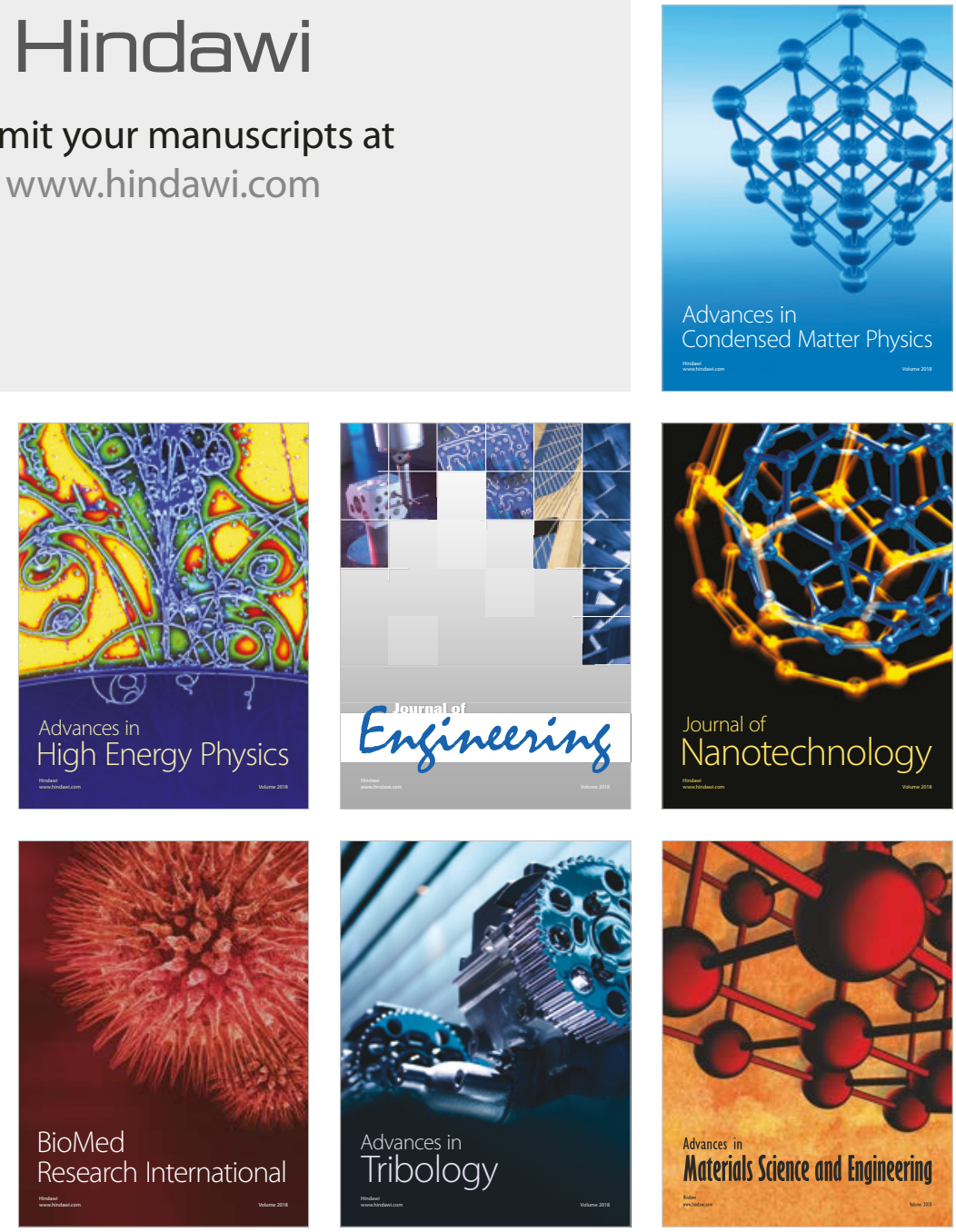